\title{
A perfect MC-ICP-MS detector array for transient signal analysis?
}

\author{
G. CRAig ${ }^{1}$, H. VOLLSTAEDT ${ }^{1}$, N. S. LlOyd ${ }^{1}$, C. \\ BOUMAN $^{1}$ AND J. SCHWIETERS ${ }^{1}$
}

${ }^{1}$ Thermo Fisher Scientific, Hanna-Kunath Str. 11, 28199

Bremen, Germany (*correspondance:

grant.craig@thermofisher.com)

The core design of the detector arrays in current commercially available multicollector inductively coupled plasma mass spectrometers (MC-ICP-MS) were concieved prior to the popularity of coupling MC-ICP-MS to transient sample introduction systems: such as laser ablation (LA) and gas chromatography (GC). As these techniques have been adopted sources of imprecision and bias occurring from the detection array have been observed.

The sources of error identified have included: tau decay factors ${ }^{1}$, blind-time ${ }^{2}$, time lag $^{3}$ and spectral skew ${ }^{4}$. Softwarebased corrections, either internal or external to the software supplied by the instrument manufacturer, have been developed to tackle one or more source of error. However, not all of them are amenable to post-measurement correction and deeper design changes are required.

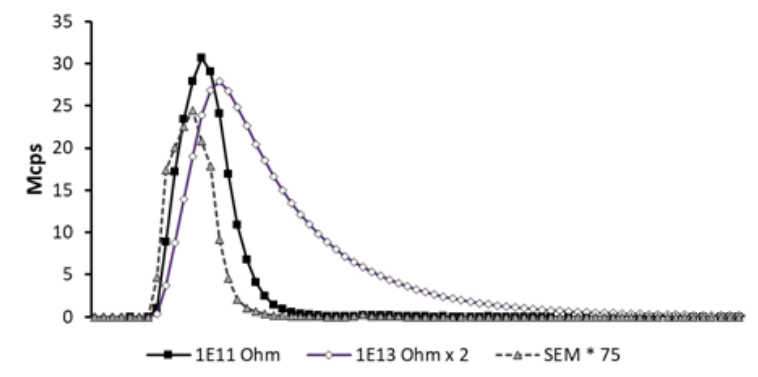

Figure 1: Transient signal profile of three different detectors

Here we report on developments to Thermo Scientific ${ }^{\mathrm{TM}}$ multicollector mobile detector array technology which incorporates multiple strategies to improve transient signal analyses. This comprehensive approach, integrating both hardware and software, moves the technology significantly closer to a theoretically perfect detector array for transient MC-ICP-MS analysis.

[1] Krupp \& Donard (2005) Int. J. Mass. Spec., 242, 233-242

[2] van Malderen et al. (2016) J. Anal. At. Spectrom., 31, 423-439

[3] Claverie et al. (2016) Anal. Chem., 88, 4375-4382

[4] van Malderen et al. (2018) Spectrochim. Acta: Part B., 140, 29-34 